Research article

\title{
Cardiovascular risk factors and acute-phase response in idiopathic ascending aortitis: a case control study
}

\author{
Vaidehi R Chowdhary ${ }^{1}$, Cynthia S Crowson ${ }^{2}$, Kimberly P Liang ${ }^{3}$, Clement J Michet Jr ${ }^{1}$, \\ Dylan V Miller ${ }^{4}$, Kenneth J Warrington ${ }^{1}$ and Eric L Matteson ${ }^{1}$
}

\begin{abstract}
1Division of Rheumatology, Department of Medicine, Mayo Clinic College of Medicine, 2001 st Street SW, Rochester, MN 55905, USA 2Division of Biostatistics, Department of Health Sciences Research, Mayo Clinic College of Medicine, 200 1st Street SW, Rochester, MN 55905, USA

3Department of Medicine and Division of Rheumatology, University of Pittsburgh Medical Center, 200 Lothrop Street, Pittsburgh, PA 15213, USA ${ }^{4}$ Division of Anatomic Pathology, Department of Laboratory Medicine and Pathology, Mayo Clinic College of Medicine, 200 1st Street SW, Rochester, MN 55905, USA
\end{abstract}

Corresponding author: Vaidehi R Chowdhary, chowdhary.vaidehi@mayo.edu

Received: 18 Nov 2008 Revisions requested: 14 Jan 2009 Revisions received: 10 Feb 2009 Accepted: 27 Feb 2009 Published: 27 Feb 2009

Arthritis Research \& Therapy 2009, 11:R29 (doi:10.1186/ar2633)

This article is online at: http://arthritis-research.com/content/11/1/R29

(c) 2009 Chowdhary et al.; licensee BioMed Central Ltd.

This is an open access article distributed under the terms of the Creative Commons Attribution License (http://creativecommons.org/licenses/by/2.0), which permits unrestricted use, distribution, and reproduction in any medium, provided the original work is properly cited.

\begin{abstract}
Introduction Idiopathic aortitis is a rare condition characterized by giant cell or lymphoplasmacytic inflammation of the aorta. The purpose of this study was to describe risk factors for the development of idiopathic aortitis.

Methods We conducted a case control study of 50 patients who were age-matched with two control subjects with noninflammatory ascending aortic aneurysms. We examined whether the prevalences of gender, hypertension, hyperlipidemia, diabetes mellitus, smoking, family history of any aortic aneurysms, and elevated inflammatory markers differed between cases and controls.

Results The mean age of cases was $71.6 \pm 8.9$ years and that of controls was $71.1 \pm 8.9$ years. We found female gender (odds ratio [OR] 2.41, 95\% confidence interval [Cl] 1.20 to $4.85 ; P=0.014$ ) and active smoking (OR $3.37,95 \% \mathrm{Cl} 1.12$ to $10.08 ; P=0.03$ ) to be associated with idiopathic aortitis. The

association with smoking persisted after adjustment for gender (OR 3.24, 95\% Cl 1.05 to $9.96 ; P=0.04$ ). There was a trend toward lower prevalence of diabetes mellitus in cases (OR 0.39, $95 \% \mathrm{Cl} 0.11$ to $1.43 ; P=0.16$ ) but no difference in prevalences of other risk factors. The median pre-operative erythrocyte sedimentation rate (ESR) was $20 \mathrm{~mm} /$ hour in cases $(n=13)$ and $9 \mathrm{~mm} /$ hour in controls $(n=22)$. The median pre-operative C-reactive protein (CRP) levels were $12 \mathrm{mg} / \mathrm{L}$ in cases $(n=8)$ and $3 \mathrm{mg} / \mathrm{L}$ in controls $(\mathrm{n}=6)$ (normal: $<8 \mathrm{mg} / \mathrm{L}$ ). A higher proportion of cases versus controls had elevations in ESR $(38 \%$ versus $9 \% ; P=0.075)$ and $\mathrm{CRP}(62 \%$ versus $0 \% ; P=0.031)$.

Conclusions Gender and smoking may interact in complex mechanisms with immune and proteolytic pathways in older, less distensible thoracic aortas. Elevated acute-phase reactants as a marker of systemic inflammation may be present in some patients.
\end{abstract}

\section{Introduction}

Aneurysms of the thoracic aorta are rare and occur with an incidence of 5.9 per 100,000 [1]. They are caused by weakening of the aortic wall from hypertension, heritable disorders like Marfan syndrome, bicuspid valve disease, and inflammatory and infectious processes. Among the systemic inflammatory diseases, thoracic aneurysms and aortitis occur in giant cell arteritis (GCA), Takayasu arteritis, anti-neutrophil cytoplasmic antibody (ANCA)-associated granulomatous vasculi- tis, spondyloarthropathies, rheumatoid arthritis, and systemic lupus erythematosus [2]. Rarely, a primary inflammatory process characterized by lymphoplasmacytic or giant cell infiltrate may be responsible. Such patients are termed to have idiopathic or isolated aortitis, a condition that is likely different from GCA or temporal arteritis.

The risk factors for development of aortic complications in GCA have been well studied [3]. The presence of an aortic

Cl: confidence interval; CRP: C-reactive protein; ESR: erythrocyte sedimentation rate; GCA: giant cell arteritis; HLA: human leukocyte antigen; MMP: matrix metalloproteinase; OR: odds ratio; PMR: polymyalgia rheumatica. 
insufficiency murmur, hypertension, coronary artery disease, hyperlipidemia, and symptoms of polymyalgia rheumatica (PMR) and elevation of systemic markers of inflammation were predictors of aneurysm development [4,5]. Persistent untreated inflammation was postulated as one mechanism for weakening of aortic wall and consequent aortic complications. A prospective study of 54 GCA patients who were screened with a defined protocol found aortic aneurysms in $22 \%$ of patients [6]. Aneurysms were more common in men and occurred less frequently in patients with hypercholesterolemia. Treatment of hypercholesterolemia with statins was postulated to be protective for aortic wall enlargement. There was no difference in the prevalences of smoking, hypertension, and diabetes in patients with or without aortic abnormalities. Interestingly, at the time of screening, patients with aneurysm/aortic dilatation had lower serum acute-phase reactants and lower relapse rates and needed shorter periods of prednisone therapy [6].

Histopathologic examination of the aortic wall revealed a paucity of inflammatory infiltrate but multiple foci of disruption of elastic lamellae, even in areas devoid of inflammation. There was increased expression of matrix metalloproteinase (MMP)2 in the temporal artery as well as aortic tissue, whereas MMP9 was found only in temporal artery specimens with active inflammation [6]. Thus, the process of aneurysm formation in systemic inflammatory diseases is complex, multifactorial, and likely involves immune and proteolytic pathways.

The risk factors for development of idiopathic aortitis are not known. The problem is compounded by the fact that many patients are diagnosed post-operatively after histopathologic review of the surgical specimen reveals giant cell inflammation. Information on pre-operative traditional markers of inflammation such as erythrocyte sedimentation rate (ESR) and C-reactive protein (CRP) is scanty [7-9]. In this case control study, we examined whether traditional cardiovascular risk factors differed in patients with idiopathic aortitis compared with patients with non-inflammatory aneurysms. We also assessed the frequency of abnormal pre-operative ESR and CRP in these patients.

\section{Materials and methods Subjects}

Medical records of all patients at least 18 years old who underwent surgical resection for ascending aortic aneurysm from 1 January 2000 until 31 July 2006 were searched by means of a database of pathology specimens. Patients with giant cell or lymphoplasmacytic aortic inflammation were identified, and the histopathology slides were reviewed (DVM). Individuals with aortitis due to identifiable systemic rheumatic diseases, infectious diseases, and heritable diseases (Marfan syndrome, bicuspid aortic valve, and Ehlers-Danlos syndrome) were excluded from the analyses. Individuals who declined to have their medical records used for research were also excluded.
Patients with idiopathic aortitis constituted our case group. The cohort of patients serving as controls was drawn from patients who were undergoing ascending aortic aneurysm repair during the same period and who fulfilled the exclusion criteria and did not have giant cell or lymphoplasmacytic inflammation in the wall of the resected aorta. For each case, two control subjects matched on age ( \pm 5 years) and year of surgery were randomly selected from the pool of all controls with non-inflammatory non-infectious aneurysm.

\section{Data collection}

Age, gender, and race were abstracted from the patient medical records. Cardiovascular risk factors assessed included gender, presence of hypertension, diabetes mellitus (types I and II), hyperlipidemia, family history of aneurysms, and smoking. Presence of hypertension, hyperlipidemia, or diabetes mellitus at the time of surgery was identified in the medical record by ICD-9 (International Statistical Classification of Diseases and Related Health Problems, ninth revision) coding or by physician diagnosis or the patient provided information on medical and family history during their visits to the Mayo Clinic (Rochester, MN, USA). Family history of any aortic aneurysm was collected from clinical records or patient family history forms. Smoking history at the time of surgery was classified as never, current (within last 30 days), or former (quit more than 30 days ago). ESR and CRP values were recorded if they had been measured within a month pre-operatively.

\section{Statistical analysis}

Descriptive statistics were used to summarize the data (mean, median, proportions, and so on). The association between case/control status and cardiovascular risk factors was examined by means of logistic regression models. Each cardiovascular risk factor was examined individually and after adjustment for gender. Analyses are reported as odds ratio (OR) with corresponding 95\% confidence intervals (Cls). The Fisher exact test was used to analyze percentage of cases versus controls with pre-operative elevation in ESR and CRP. In all cases, two-tailed $P$ values of less than 0.05 were used to denote statistical significance. For risk factors with a prevalence of $25 \%$ to $50 \%$, the study had $80 \%$ power to detect an OR of 2.9. For risk factors with a lower prevalence (for example, $10 \%$ ) or a higher prevalence (for example, $70 \%$ ), this study had $80 \%$ power to detect an OR of 4.0. The study was approved by the Mayo Clinic Institutional Review Board (number 08-008786) and was conducted according to its guidelines.

\section{Results \\ Subjects}

We identified 75 cases of non-infectious aortitis from patients who had undergone surgical repair during the study period. Of these, 25 cases were excluded, including patients with a history of GCA/PMR $(n=15)$, inflammatory arthritis $(n=2)$, Takayasu arteritis and Crohn disease $(n=1$ each), bicuspid aortic 
valve $(n=3)$, and Marfan syndrome $(n=1)$. Two additional patients, one with a history of thymoma and one mislabeled as having aortitis without evidence of inflammation in the surgical specimen, were excluded. The clinical features, imaging findings, and surgical outcomes of 43 of these 50 patients with idiopathic aortitis have been described previously [10,11]. The control group consisted of 100 patients matched on age and year of surgery. The mean age of cases ( \pm standard deviation) was $71.6 \pm 8.9$ years and that of controls was $71 \pm 8.9$ years $(P=0.69)$.

\section{Risk factors}

The prevalence of cardiovascular risk factors is summarized in Table 1. Female gender was a risk factor for development of idiopathic aortitis (OR $2.41,95 \% \mathrm{Cl} 1.20$ to $4.85 ; P=0.014$ ). To reduce the probability of selection bias, we then compared the gender distribution of the 100 controls (69\% were male) with that of the remaining 659 unselected controls $(71.5 \%$ were male) from the pool of all patients undergoing surgery for this indication. There was no difference in gender distribution between the selected and unselected controls $(P=0.61)$.

The prevalences of hypertension, hyperlipidemia, and family history of aortic aneurysms were similar in cases and controls (Table 1). The prevalence of current smokers was higher in cases as compared with controls (OR 3.37, 95\% Cl 1.12 to 10.08; $P=0.02$ ). There was no difference in prevalence of former or never smokers between the groups. A trend toward a lower prevalence of diabetes mellitus was seen in cases as compared with controls (OR $0.39,95 \% \mathrm{Cl} 0.11$ to $1.43 ; P=$ $0.14)$.

To evaluate whether gender differences between cases and controls were masking the differences in cardiovascular risk factors, we performed gender-adjusted analyses (Table 1). There was no difference in prevalence of hypertension (OR $1.27,95 \% \mathrm{Cl} 0.57$ to $2.81 ; P=0.56$ ), hyperlipidemia (OR $0.84,95 \% \mathrm{Cl} 0.42$ to $1.69 ; P=0.63$ ), or family history of aortic aneurysms (OR $1.37,95 \% \mathrm{Cl} 0.46$ to $4.06 ; P=0.57$ ). The prevalence of current smokers continued to be higher even after adjustment for gender (OR 3.24, 95\% Cl 1.05 to 9.96; $P$ $=0.04)$. There was a trend toward a lower prevalence of diabetes mellitus in patients with idiopathic aortitis (OR 0.44 , $95 \% \mathrm{Cl} 0.12$ to $1.64 ; P=0.22)$.

\section{Acute-phase reactants}

The pre-operative ESR and CRP measurements in the cases and controls are presented in Table 2. ESR was determined in 13 cases and 22 controls. The median values were $20 \mathrm{~mm} /$ hour in cases and $9 \mathrm{~mm} /$ hour in controls. Among those tested, a higher proportion of cases had an elevated ESR as compared with controls (38\% versus $9 \% ; P=0.075$ ). The median level of CRP was higher in cases among patients in whom the test was performed ( $n=8, C R P=12 \mathrm{mg} / \mathrm{L}$ ) versus controls ( $\mathrm{n}=6, \mathrm{CRP}=3 \mathrm{mg} / \mathrm{L} ; P=0.010$ ). A significantly higher proportion of cases had an elevated CRP as compared with controls $(62 \%$ versus none; $P=0.031)$.

\section{Discussion}

To our knowledge, this is the first study to identify risk factors for development of idiopathic aortitis. Factors independently associated with an increased risk for idiopathic aortitis discovered at the time of surgical thoracic aneurysm repair in this study were female gender and active smoking. We did not find any difference in the prevalence of hypertension, hyperlipidemia, or family history of any aortic aneurysm. We found a trend, though not statistically significant, toward a lower prevalence of diabetes mellitus in cases versus controls.

\section{Table 1}

Comparison of cardiovascular risk factors in cases with idiopathic aortitis and control patients with non-inflammatory ascending thoracic aortic aneurysms

\begin{tabular}{|c|c|c|c|c|}
\hline & $\begin{array}{c}\text { Cases } \\
(n=50)\end{array}$ & $\begin{array}{l}\text { Controls } \\
(n=100)\end{array}$ & $\begin{array}{l}\text { Odds ratio } \\
(95 \% \mathrm{Cl})\end{array}$ & $\begin{array}{c}\text { Odds ratio } \\
(95 \% \mathrm{Cl}) \\
\text { adjusted for gender }\end{array}$ \\
\hline Gender female, percentage & 52 & 31 & $2.41(1.20,4.85)$ & \\
\hline Hypertension, percentage & 76 & 69 & $1.42(0.66,3.09)$ & $1.27(0.57,2.81)$ \\
\hline Hyperlipidemia, percentage & 45 & 51 & $0.78(0.39,1.56)$ & $0.84(0.42,1.69)$ \\
\hline Diabetes mellitus, percentage & 6 & 14 & $0.39(0.11,1.43)$ & $0.44(0.12,1.64)$ \\
\hline \multicolumn{5}{|l|}{ Smoking, percentage } \\
\hline Current & 18 & 6 & & \\
\hline Former & 52 & 62 & $3.37(1.12,10.08)^{a}$ & $3.24(1.05,9.96)$ \\
\hline Never & 30 & 32 & & \\
\hline Family history of aortic aneurysms, percentage & 15 & 10 & $1.61(0.56,4.63)$ & $1.37(0.46,4.06)$ \\
\hline
\end{tabular}

aCurrent versus never or former smokers. $\mathrm{Cl}$, confidence interval. 
Table 2

Pre-operative erythrocyte sedimentation rate and C-reactive protein in cases with idiopathic aortitis compared with control patients with non-inflammatory aortic aneurysms

\begin{tabular}{lcc}
\hline & Cases & Controls \\
\hline Pre-operative ESR & & 22 \\
$\quad$ Number tested & 13 & \\
Pre-operative ESR, mm/hour & $20.5 \pm 11.6$ & $11.3 \pm 11.1$ \\
$\quad$ Mean \pm SD & $20(2-40)$ & $9(0-40)$ \\
$\quad$ Median (range) & $38 \%$ & $9 \%$ \\
Subjects with elevated ESR & 5.024 \\
Pre-operative CRP & 5.075 \\
$\quad$ Number tested & & 6 \\
Pre-operative CRP, mg/L & $35 \pm 50$ & $3 \pm 0.7$ \\
$\quad$ Mean \pm SD & $12(2.5-119)$ & $3(1.2-3.2)$ \\
$\quad$ Median (range) & $60 \%$ & $0 \%$ \\
Subjects with elevated CRP, percentage & & 0.010 \\
\hline
\end{tabular}

$\mathrm{CRP}, \mathrm{C}$-reactive protein; ESR, erythrocyte sedimentation rate; SD, standard deviation.

The mechanism by which female gender predisposes to inflammation in the thoracic aorta is not known. The development of disease in older post-menopausal females suggests a role of sex hormones. Human aortic matrix is composed of collagen, which plays a role in load bearing, and elastin, which conveys elasticity to the aorta. Sex hormones play an important role in aortic wall compliance by regulating the elastin/collagen activity [12-14]. 17- $\beta$-Estradiol increases the elastin/ collagen ratio, reflecting an increase in distensibility of aorta and consequently lower systolic blood pressure [15]. In animal models, oophorectomy increases collagen synthesis and decreases aortic distensibility [16]. Whether these hormones interact with immunologic and proteolytic systems to modulate inflammation in the stiff non-compliant older aorta merits further study.

We also found active smoking to be associated with an increased risk of idiopathic aortitis. The lack of any association with former or never smoking status indicates an acute but not cumulative effect. Smoking is an important risk factor for many rheumatic diseases like lupus and increases the risk of seropositivity in rheumatoid arthritis patients, especially those who are positive for shared epitope $[17,18]$. Smoking is the single most important factor for initiation and rapid growth of abdominal aortic aneurysms, and more patients with inflammatory abdominal aortic aneurysms tend to be smokers [19-27]. Smoking plays important roles in mediating atherosclerosis, elastolytic response, and potentiating inflammation [28-30]. It affects key proteolytic enzymes like MMPs, elastases, cysteine proteases, and lipoxygenases that are important for extracellular matrix degradation and aneurysm formation [31,32]. Exposure of endothelial cells to cigarette smoke increases MMP-1,
MMP-8, and MMP-9 levels [33]. High serum levels of MMP-9 are found in moderate-diameter abdominal aortic aneurysms [34]. The importance of these processes is underscored by the fact that diabetic patients, in spite of their increased risk for atherosclerotic vascular disease, are at lower risk of abdominal aortic aneurysm $[35,36]$. Incubation of monocytes with glycated type 1 collagen matrices reduced the secretion of MMP2, MMP-9, and IL-6 [37]. This may be one mechanism explaining why aneurysmal growth rate is slower in diabetic patients.

Smoking may also interact in complex mechanisms with immune response genes like human leukocyte antigen (HLA) to mediate vascular inflammation in predisposed individuals. In patients with inflammatory abdominal aortic aneurysms, active smoking and female gender were associated with high-grade tissue inflammation [21]. HLA-DR $B 1{ }^{*} 01$ has been reported to be protective and HLA-DR B1 02 and HLA-DR B1 *04 (DR4, 0401 allele) were significantly associated with increased risk of tissue inflammation [21,38].

Though tested in only a subset of patients in our study, preoperative ESR and CRP were elevated in a higher proportion of cases than controls. However, these elevations were much lower when compared with temporal arteritis patients with aortitis whose ESR levels range from 82 to $101 \mathrm{~mm} /$ hour [4-6]. It is unclear whether these markers should be determined preoperatively in all patients undergoing aortic aneurysm repair or what the clinical consequence of elevated markers of inflammation should be in terms of potential therapy and follow-up.

The strength of our study is rigorous case definition with availability of histopathology in cases and controls. The case con- 
trol design allowed us to study multiple risk factors for this very rare condition. The identification of risk factors is important for therapeutic intervention. Smoking cessation may slow down the inflammatory process and consequent growth of aneurysm [39]. Advances in molecular pathogenesis will pave the way for future therapies. Due to their anti-oxidant property, angiotensin-converting enzyme inhibitors have been reported to normalize impaired bradykinin-mediated endothelium-dependent venodilatation in smokers [40], and inhibition of MMP-9 by doxycycline was useful in preventing aneurysm growth [41,42].

The potential weaknesses of the study include the inclusion of surgical cases only. There may be a spectrum of disease, with mild disease not coming to medical attention. Inclusion of only cases with surgical specimens as the standard for evaluating inflammation was chosen to increase the internal validity of the study. Cases were selected from a large tertiary care referral center, perhaps introducing a potential bias for more severe disease. We have not analyzed the risk factors according to the histopathologic subsets of giant cell or lymphoplasmacytic inflammation; however, data from our retrospective cohort did not find any meaningful correlation between clinical features and histopathology due to small numbers (manuscript in preparation).

\section{Conclusion}

Female gender and active smoking are risk factors for development of idiopathic aortitis. Future studies are needed to evaluate the utility of smoking cessation, the role of measurement of inflammatory markers, and medical treatment strategies on disease progress and outcome.

\section{Competing interests}

The authors declare that they have no competing interests.

\section{Authors' contributions}

VRC conceived of the study and participated in study design, data acquisition, data interpretation, and manuscript preparation. CSC carried out statistical analysis. KPL, CJM, KJW, and ELM participated in study design and data interpretation. DVM carried out the pathologic review of aortic specimens. All authors read and approved the final manuscript.

\section{Acknowledgements}

We are grateful to Darrell R Schroeder and Hilal M Kremers for valuable input in planning this study. This article was made possible by grant 1 UL1 RR024150 from the National Center for Research Resources (NCRR), a component of the National Institutes of Health (NIH), and the NIH Roadmap for Medical Research. Its contents are solely the responsibility of the authors and do not necessarily represent the official view of the NCRR or the NIH.

\section{References}

1. Bickerstaff LK, Pairolero PC, Hollier LH, Melton $\sqcup$, Van Peenen HJ, Cherry KJ, Joyce JW, Lie JT: Thoracic aortic aneurysms: a population-based study. Surgery 1982, 92:1103-1108.
2. Slobodin G, Naschitz JE, Zuckerman E, Zisman D, Rozenbaum M, Boulman N, Rosner I: Aortic involvement in rheumatic diseases. Clin Exp Rheumatol 2006, 24(2 Suppl 41):S41-47.

3. Evans JM, O'Fallon WM, Hunder GG: Increased incidence of aortic aneurysm and dissection in giant cell (temporal) arteritis. A population-based study. Ann Intern Med 1995, 122:502-507.

4. Nuenninghoff DM, Hunder GG, Christianson TJ, McClelland RL, Matteson EL: Incidence and predictors of large-artery complication (aortic aneurysm, aortic dissection, and/or large-artery stenosis) in patients with giant cell arteritis: a populationbased study over $\mathbf{5 0}$ years. Arthritis Rheum 2003, 48:3522-3531.

5. Gonzalez-Gay MA, Garcia-Porrua C, Piñeiro A, Pego-Reigosa R, Llorca J, Hunder GG: Aortic aneurysm and dissection in patients with biopsy-proven giant cell arteritis from northwestern Spain: a population-based study. Medicine (Baltimore) 2004, 83:335-341.

6. García-Martínez A, Hernández-Rodríguez J, Arguis P, Paredes P, Segarra M, Lozano E, Nicolau C, Ramírez J, Lomeña F, Josa M, Pons F, Cid MC: Development of aortic aneurysm/dilatation during the followup of patients with giant cell arteritis: a crosssectional screening of fifty-four prospectively followed patients. Arthritis Rheum 2008, 59:422-430.

7. Rojo-Leyva F, Ratliff NB, Cosgrove DM 3rd, Hoffman GS: Study of 52 patients with idiopathic aortitis from a cohort of 1,204 surgical cases. Arthritis Rheum 2000, 43:901-907.

8. Miller DV, Isotalo PA, Weyand CM, Edwards WD, Aubry MC, Tazelaar HD: Surgical pathology of noninfectious ascending aortitis: a study of $\mathbf{4 5}$ cases with emphasis on an isolated variant. Am J Surg Pathol 2006, 30:1150-1158.

9. Kerr LD, Chang YJ, Spiera H, Fallon JT: Occult active giant cell aortitis necessitating surgical repair. J Thorac Cardiovasc Surg 2000, 120:813-815.

10. Liang KP, Chowdhary VR, Michet CJ, Miller DV, Sundt TM, Matteson EL, Warrington KJ: Non-infectious ascending aortitis: a clinicopathologic review of 62 cases. Clin Exp Rheumatol 2007, 25(Suppl 44):S106.

11. Mennander AA, Miller DV, Liang KP, Warrington KJ, Connolly HM, Schaff HV, Sundt TM: Surgical management of ascending aortic aneurysm due to non-infectious aortitis. Scand Cardiovasc $J$ 2008, 42:417-424.

12. Dart AM, Kingwell BA, Gatzka CD, Willson $K$, Liang $Y L$, Berry KL, Wing LM, Reid CM, Ryan P, Beilin LJ, Jennings GL, Johnston $\mathrm{Cl}$, McNeil JJ, MacDonald GJ, Morgan TO, West MJ, Cameron JD: Smaller aortic dimensions do not fully account for the greater pulse pressure in elderly female hypertensives. Hypertension 2008, 51:1129-1134.

13. Waddell TK, Dart AM, Gatzka CD, Cameron JD, Kingwell BA: Women exhibit a greater age-related increase in proximal aortic stiffness than men. J Hypertens 2001, 19:2205-2212.

14. Waddell TK, Rajkumar C, Cameron JD, Jennings GL, Dart AM, Kingwell BA: Withdrawal of hormonal therapy for 4 weeks decreases arterial compliance in postmenopausal women. $J$ Hypertens 1999, 17:413-418.

15. Natoli AK, Medley TL, Ahimastos AA, Drew BG, Thearle DJ, Dilley RJ, Kingwell BA: Sex steroids modulate human aortic smooth muscle cell matrix protein deposition and matrix metalloproteinase expression. Hypertension 2005, 46:1129-1134.

16. Fischer GM, Swain ML: Effects of estradiol and progesterone on the increased synthesis of collagen in atherosclerotic rabbit aortas. Atherosclerosis 1985, 54:177-185.

17. Costenbader KH, Kim DJ, Peerzada J, Lockman S, Nobles-Knight $D$, Petri M, Karlson EW: Cigarette smoking and the risk of systemic lupus erythematosus: a meta-analysis. Arthritis Rheum 2004, 50:849-857.

18. Sugiyama D, Nishimura K, Tamaki K, Tsuji G, Nakazawa T, Morinobu A, Kumagai S: Impact of smoking as a risk factor for developing rheumatoid arthritis: a meta-analysis of observational studies. Ann Rheum Dis 2009 in press.

19. Sakalihasan N, Limet R, Defawe OD: Abdominal aortic aneurysm. Lancet 2005, 365:1577-1589.

20. Nitecki SS, Hallett JW Jr, Stanson AW, Ilstrup DM, Bower TC, Cherry KJ Jr, Gloviczki P, Pairolero PC: Inflammatory abdominal aortic aneurysms: a case-control study. J Vasc Surg 1996, 23:860-868. discussion 868-869. 
21. Rasmussen TE, Hallett JW Jr, Tazelaar HD, Miller VM, Schulte S, O'Fallon WM, Weyand CM: Human leukocyte antigen class II immune response genes, female gender, and cigarette smoking as risk and modulating factors in abdominal aortic aneurysms. J Vasc Surg 2002, 35:988-993.

22. Lee AJ, Fowkes FG, Carson MN, Leng GC, Allan PL: Smoking, atherosclerosis and risk of abdominal aortic aneurysm. Eur Heart J 1997, 18:671-676.

23. Lederle FA, Johnson GR, Wilson SE, Chute EP, Hye RJ, Makaroun MS, Barone GW, Bandyk D, Moneta GL, Makhoul RG: The aneurysm detection and management study screening program: validation cohort and final results. Aneurysm Detection and Management Veterans Affairs Cooperative Study Investigators. Arch Intern Med 2000, 160:1425-1430.

24. Lindblad B, Borner G, Gottsater A: Factors associated with development of large abdominal aortic aneurysm in middleaged men. Eur J Vasc Endovasc Surg 2005, 30:346-352.

25. Madaric J, Vulev I, Bartunek J, Mistrik A, Verhamme K, De Bruyne $B$, Riecansky I: Frequency of abdominal aortic aneurysm in patients $>60$ years of age with coronary artery disease. $A m \mathrm{~J}$ Cardiol 2005, 96:1214-1216.

26. Lederle FA, Nelson DB, Joseph AM: Smokers' relative risk for aortic aneurysm compared with other smoking-related diseases: a systematic review. J Vasc Surg 2003, 38:329-334.

27. Brady AR, Thompson SG, Fowkes FG, Greenhalgh RM, Powell JT: Abdominal aortic aneurysm expansion: risk factors and time intervals for surveillance. Circulation 2004, 110:16-21.

28. Yasue H, Hirai N, Mizuno Y, Harada E, Itoh T, Yoshimura M, Kugiyama $\mathrm{K}$, Ogawa $\mathrm{H}$ : Low-grade inflammation, thrombogenicity, and atherogenic lipid profile in cigarette smokers. Circ J 2006, 70:8-13.

29. Kakafika Al, Mikhailidis DP: Smoking and aortic diseases. Circ J 2007, 71:1173-1180.

30. Karimi K, Sarir H, Mortaz E, Smit JJ, Hosseini H, De Kimpe SJ, Nijkamp FP, Folkerts G: Toll-like receptor-4 mediates cigarette smoke-induced cytokine production by human macrophages. Respir Res 2006, 7:66.

31. Halpern VJ, Mathrumbutham M, Lagraize C, Rao SK, Faust GR, Cohen JR: Reduced protease inhibitory capacity in patients with abdominal aortic aneurysms is reversed with surgical repair. J Vasc Surg 2002, 35:792-797.

32. Cannon DJ, Read RC: Blood elastolytic activity in patients with aortic aneurysm. Ann Thorac Surg 1982, 34:10-15.

33. Nordskog BK, Blixt AD, Morgan WT, Fields WR, Hellmann GM: Matrix-degrading and pro-inflammatory changes in human vascular endothelial cells exposed to cigarette smoke condensate. Cardiovasc Toxicol 2003, 3:101-117.

34. McMillan WD, Tamarina NA, Cipollone M, Johnson DA, Parker MA, Pearce WH: Size matters: the relationship between MMP-9 expression and aortic diameter. Circulation 1997, 96:2228-2232.

35. Pleumeekers HJ, Hoes AW, Does E van der, van Urk H, Hofman A, de Jong PT, Grobbee DE: Aneurysms of the abdominal aorta in older adults. The Rotterdam Study. Am J Epidemiol 1995, 142:1291-1299.

36. Lederle FA, Johnson GR, Wilson SE, Chute EP, Littooy FN, Bandyk D, Krupski WC, Barone GW, Acher CW, Ballard DJ: Prevalence and associations of abdominal aortic aneurysm detected through screening. Aneurysm Detection and Management (ADAM) Veterans Affairs Cooperative Study Group. Ann Intern Med 1997, 126:441-449.

37. Golledge J, Karan M, Moran CS, Muller J, Clancy P, Dear AE, Norman PE: Reduced expansion rate of abdominal aortic aneurysms in patients with diabetes may be related to aberrant monocyte-matrix interactions. Eur Heart J 2008, 29:665-672.

38. Monux G, Serrano FJ, Vigil P, De la Concha EG: Role of HLA-DR in the pathogenesis of abdominal aortic aneurysm. Eur $J$ Vasc Endovasc Surg 2003, 26:211-214.

39. MacSweeney ST, Ellis M, Worrell PC, Greenhalgh RM, Powell JT: Smoking and growth rate of small abdominal aortic aneurysms. Lancet 1994, 344:651-652.

40. Chalon S, Moreno H Jr, Hoffman BB, Blaschke TF: Angiotensinconverting enzyme inhibition improves venous endothelial dysfunction in chronic smokers. Clin Pharmacol Ther 1999, 65:295-303.

41. Hackmann AE, Rubin BG, Sanchez LA, Geraghty PA, Thompson RW, Curci JA: A randomized, placebo-controlled trial of doxy- cycline after endoluminal aneurysm repair. J Vasc Surg 2008 , 48:519-526. discussion 526.

42. Chung AW, Yang HH, Radomski MW, van Breemen C: Long-term doxycycline is more effective than atenolol to prevent thoracic aortic aneurysm in marfan syndrome through the inhibition of matrix metalloproteinase-2 and -9. Circ Res 2008, 102:e73-85. 